\title{
Plasma adrenomedullin is associated with short-term mortality and vasopressor requirement in patients admitted with sepsis
}

Rossella Marino ${ }^{1}$, Joachim Struck ${ }^{2,3}$, Alan S Maisel ${ }^{4}$, Laura Magrini ${ }^{1}$, Andreas Bergmann ${ }^{2,3}$ and Salvatore Di Somma ${ }^{* *}$

\begin{abstract}
Introduction: The incidence of death among patients admitted for severe sepsis or septic shock is high. Adrenomedullin (ADM) plays a central role in initiating the hyperdynamic response during the early stages of sepsis. Pilot studies indicate an association of plasma ADM with the severity of the disease. In the present study we utilized a novel sandwich immunoassay of bioactive plasma ADM in patients hospitalized with sepsis in order to assess the clinical utility.

Methods: We enrolled 101 consecutive patients admitted to the emergency department with suspected sepsis in this study. Sepsis was defined by fulfillment of at least two systemic inflammatory response syndrome (SIRS) criteria plus clinical suspicion of infection. Plasma samples for ADM measurement were obtained on admission and for the next four days. The 28-day mortality rate was recorded.
\end{abstract}

Results: ADM at admission was associated with severity of disease (correlation with Acute Physiology and Chronic Health Evaluation II (APACHE II) score: $r=0.46 ; P<0.0001$ ). ADM was also associated with 28-day mortality (ADM median (IQR): survivors: 50 (31 to 77) pg/mL; non-survivors: 84 (48 to 232) pg/mL; $P<0.001$ ) and was independent from and additive to APACHE II $(P=0.02)$. Cox regression analysis revealed an additive value of serial measurement of ADM over baseline assessment for prediction of 28-day mortality $(P<0.01)$. ADM was negatively correlated with mean arterial pressure $(r=-0.39 ; P<0.0001)$, and it strongly discriminated those patients requiring vasopressor therapy from the others (ADM median (IQR): no vasopressors 48 (32 to 75) pg/mL; with vasopressors 129 (83 to 264) pg/mL, $P<0.0001$ ).

Conclusions: In patients admitted with sepsis, severe sepsis or septic shock plasma ADM is strongly associated with severity of disease, vasopressor requirement and 28-day mortality.

\section{Introduction}

The global incidence of severe sepsis is greater than of either cancer or myocardial infarction, with a mortality rate estimated at $40 \%$ [1-3]. This high mortality is in many cases linked to multi-organ hypoperfusion and hypotension associated with the development of septic shock. As the clinical and laboratory findings of sepsis are nonspecific and culture results are not readily available, the diagnosis and risk stratification of patients is often delayed [4]. Biomarkers such as C-reactive protein (CRP), leukocyte count, lactate and Procalcitonin (PCT) are often used to differentiate between systemic inflammatory response syndrome (SIRS), sepsis, severe sepsis and septic shock as well as for patient risk stratification [5-7].

\footnotetext{
* Correspondence: salvatore.disomma@uniroma1.it

'University La Sapienza Rome, Sant'Andrea Hospital, Rome, Italy

Full list of author information is available at the end of the article
}

Adrenomedullin (ADM) is a peptide first isolated from a human pheochromocytoma [8], and has been found to be elevated in plasma of sepsis patients [9-11]. The mechanism of secretion of ADM in large part relates to the effects of lipopolysaccharide (LPS) stimulation [12]. Previous studies indicate that ADM plays a major role in initiating the hyperdynamic response during the early stages of polymicrobial sepsis $[13,14]$. Due to the cumbersome competitive immunoassays requiring extraction of large sample volumes, thus far plasma ADM has been determined only in a small number of sepsis patients [9,15-17]. Therefore, the potential value of determining plasma ADM in such patients cannot yet be ascertained. Recently, a new double-monoclonal antibody sandwich immunoassay for the measurement of human mature ADM has been developed facilitating the reliable and simple assessment of this biomarker [18]. The assay selectively 
detects the C-terminally amidated form of ADM, which in contrast to the glycine-extended ADM variant is bioactive. Our study aimed to explore the clinical utility of basal and serial plasma ADM assessments in patients hospitalized for sepsis using this new assay.

\section{Materials and methods Patient population}

This was a prospective observational study performed in the Emergency Department (ED) Sant'Andrea Hospital University La Sapienza Rome, from December 2011 to April 2012. Patients presenting to the ED with suspected sepsis according to the Surviving Sepsis Campaign guidelines [19] and need for hospitalization were considered eligible for the study. We enrolled 101 consecutives patients (61 males and 40 females) with median (IQR) age 78 (72 to 83 ) years. Numerous comorbidities such as diabetes and hypertension were present: $29 \%$ of the patients had severe sepsis or septic shock on admission (Table 1).

All patients gave informed written consent according to the Helsinki declaration. The study was approved by the ethical committee of Sant' Andrea Hospital in Rome. Anamnestic data, physical examination, electrocardiogram, routine laboratory test, and instrumental radiologic examinations were performed for each patient. At arrival and for the first 4 days after hospitalization all patients underwent monitoring of vital parameters, including temperature, physical examination, arterial blood analysis, and fluid balance. The acute physiology and chronic health evaluation II (APACHE II) score was calculated during the first 24 hours after admission [20]. During hospitalization therapy, physical examination, fluid balance, vital parameters and culture examinations were recorded on a clinical research form. Survival was recorded daily by in-hospital observation and later by phone call, respectively, over a period of 28 days after admission to the ED.

\section{ADM measurement}

Ethylenediaminetetraacetic acid (EDTA) plasma samples for measurement of ADM were obtained at arrival in ED and on the next 4 days during hospitalization. Aliquots for $\mathrm{ADM}$ measurement were stored at $-40^{\circ} \mathrm{C}$ and then measured in a blinded fashion batch-wise using a recently developed immunoassay [18]: The ADM assay is a one-step sandwich-coated tube chemiluminescence immunoassay, based on Acridinium NHS-ester labeling for the detection of human ADM in unprocessed, neat plasma. It employs two mouse monoclonal antibodies, one directed against the mid region (solid phase), the other directed against the amidated C-terminal moiety of ADM (labeled antibody). Polystyrene tubes (Greiner Bio-One GmbH, Frickenhausen, Germany) were coated with the anti-mid-regional antibody (per tube $1.5 \mu \mathrm{g}$ antibody in $300 \mu \mathrm{L}$ of $50 \mathrm{mmol} / \mathrm{L}$ Tris, $100 \mathrm{mmol} / \mathrm{L} \mathrm{NaCl}, \mathrm{pH} 7.8$ ) overnight at $22^{\circ} \mathrm{C}$. Tubes
Table 1 Patient characteristics

\begin{tabular}{|c|c|}
\hline Variable & $\begin{array}{c}\text { Total population } \\
(n=101)\end{array}$ \\
\hline \multicolumn{2}{|l|}{ Demographics } \\
\hline Gender, male, n (\%) & $61(60.4)$ \\
\hline Age, years, median (IQR) & 78 (72 to 83 ) \\
\hline \multicolumn{2}{|l|}{ Examination variables } \\
\hline Respiratory rate, acts/minute, median (IQR) & 24 (22 to 28$)$ \\
\hline Body temperature, ${ }^{\circ} \mathrm{C}$, median (IQR) & 38.4 (36 to 38.7 ) \\
\hline Glasgow Coma Scale, points, median (IQR) & 15 (10 to 15$)$ \\
\hline Mean arterial pressure, mm Hg, median (IQR) & 83.3 (74 to 93) \\
\hline \multicolumn{2}{|l|}{ Past medical history } \\
\hline Cardiovascular, yes, n (\%) & $26(25.7)$ \\
\hline Hypertensive, yes, n (\%) & $47(46.5)$ \\
\hline Diabetes, yes, n (\%) & $35(34.7)$ \\
\hline Cancer, yes, n (\%) & $13(12.9)$ \\
\hline \multicolumn{2}{|l|}{ Labaratory variables } \\
\hline ADM, pg/mL, median (IQR) & 53.8 (37.4 to 94.0$)$ \\
\hline $\mathrm{PCT}, \mathrm{ng} / \mathrm{mL}$, median (IQR) & $2.8(0.6$ to 10.7$)$ \\
\hline Creatinine clearance, $\mathrm{mL} /$ minute, median (IQR) & 48 (23 to 77$)$ \\
\hline Creatinine, mg/dL, median (IQR) & 1.3 (0.9 to 2.4$)$ \\
\hline CRP, mg/dL, median (IQR) & 16 (6.6 to 25.6$)$ \\
\hline White cells, $10^{9}$ cells/L, median (IQR) & $12.7(6.8$ to 17.6$)$ \\
\hline Platelets, $10^{9}$ cells $/ \mathrm{L}$, median (IQR) & 213 (150 to 278$)$ \\
\hline \multicolumn{2}{|l|}{ Other } \\
\hline Final diagnosis, severe sepsis/shock, n (\%) & $29(28.7)$ \\
\hline Length of stay, days, median (IQR) & 5 (2 to 7$)$ \\
\hline Septic shock at arrival, yes, n (\%) & $25(24.8)$ \\
\hline Acute organ dysfunction, yes, n (\%) & 39 (38.6) \\
\hline APACHE II score, points, median (IQR) & $16(13$ to 21$)$ \\
\hline \multicolumn{2}{|l|}{ Treatment at baseline } \\
\hline Steroids, yes, n (\%) & $16(15.8)$ \\
\hline Vasopressors, yes, n (\%) & $18(17.8)$ \\
\hline Antibiotics, yes, n (\%) & $101(100)$ \\
\hline Fluid therapy, yes, n (\%) & $101(100)$ \\
\hline
\end{tabular}

ADM, Adrenomedullin; PCT, Procalcitonin; CRP, C-reactive protein.

were then blocked with $10 \mathrm{mmol} / \mathrm{L} \mathrm{Na}$-phosphate ( $\mathrm{pH}$ 6.5) containing 3\% Karion FP (Merck KGaA, Darmstadt, Germany) and 0.5\% BSA (protease-free) and lyophilized. The anti-C-terminal antibody $(1 \mathrm{~g} / \mathrm{L})$ was labeled by incubation with MACN-acridinium-NHS (N-hydroxysuccinimide)-ester ( $1 \mathrm{~g} / \mathrm{L}$; InVent $\mathrm{GmbH}$, Hennigsdorf, Germany) in a 1:5 molar ratio for 20 minutes at $22^{\circ} \mathrm{C}$. The reaction was stopped by addition of $1 / 5$ volume of $50 \mathrm{mmol} / \mathrm{L}$ glycine for 10 minutes at $22^{\circ} \mathrm{C}$. Labeled antibody was separated from free label by size exclusion chromatography first on a Centri Pure P5 Hydrated gel filtration column (emp Biotech $\mathrm{GmbH}$, Berlin, Germany) and followed by a Bio-Silect ${ }^{\circledR}$ Sec 
400-5 column (Bio-Rad Laboratories GmbH, München, Germany) for HPLC. For the immunoassay the labeled antibody was diluted into assay buffer $(300 \mathrm{mmol} / \mathrm{L} \mathrm{K}$-phosphate; $100 \mathrm{mmol} / \mathrm{L} \mathrm{NaCl} ; 10 \mathrm{mmol} / \mathrm{L}$ sodium EDTA; $5 \mathrm{~g} / \mathrm{L}$ BSA (protease-free) (Sigma); $1 \mathrm{~g} / \mathrm{L}$ each of nonspecific bovine and mouse IgG; 0.9 g/L Na-azide; 20 tabs/L Protease Inhibitor Cocktail (Roche Diagnostics $\mathrm{GmbH}$, Penzberg, Germany); $10 \mu \mathrm{mol} / \mathrm{L}$ Amastatin; $20 \mu \mathrm{mol} / \mathrm{L}$ Leupeptin; $\mathrm{pH}$ 7.0). Dilutions of full-length human ADM peptide (American Peptide Company, Sunnyvale, CA, USA) in Calibrator Dilution Buffer $(10 \mathrm{mmol} / \mathrm{L}$ Tris; $250 \mathrm{mmol} / \mathrm{L} \mathrm{NaCl}$; 2 g/L Triton X-100; 50 g/L BSA (protease-free); 20 tabs/L Protease Inhibitor Cocktail (Roche AG); pH 7.0) served as calibrators. The immunoassay was performed as follows: $50 \mu \mathrm{L}$ of plasma samples/calibrators and $200 \mu \mathrm{L}$ of labeled detection antibody $(800,000$ relative light units (RLU) per $200 \mu \mathrm{L}$ ) were pipetted in the coated tubes. The assay was incubated for 18 hours at $4^{\circ} \mathrm{C}$. Unbound tracer was removed by washing five times with wash solution $(1 \mathrm{~mL}$ each). Tube-bound chemiluminescence was measured for $1 \mathrm{~s}$ using the LB953 Multi-Tube Luminometer (BERTHOLD TECHNOLOGIES GmbH \& Co. KG, Bad Wildbad, Germany). The analytical assay sensitivity was $2 \mathrm{pg} / \mathrm{mL}$. The median ADM concentration of 200 healthy subjects was $20.7 \mathrm{pg} / \mathrm{mL}$; the 99 th percentile was $43 \mathrm{pg} / \mathrm{mL}$. The ADM sandwich assay used is not commercially available, but has been provided for research purposes by Sphingotec $\mathrm{GmbH}$.

\section{MR-proADM measurement}

Admission EDTA plasma samples, which were available from 65 patients, were measured in the BRAHMS MRproADM KRYPTOR immunoassay (Thermo Fisher Scientific, Hennigsdorf, Germany) according to the instructions of the manufacturer.

\section{Statistical analysis}

Values are expressed as mean and standard deviation, median and IQR, or count and percentage as appropriate. The nonparametric Spearman correlation coefficient is given to describe the association between continuous variables. Group comparisons were performed using nonparametric tests (Kruskal-Wallis test for continuous variables and chi-square $\left(\chi^{2}\right)$ test with simulated $P$-values using 2,000 replicates for categorical data). Biomarker data were log-transformed. To analyze the effect of individual risk factors on survival, univariable Cox proportionalhazards regression was calculated. The assumption of proportional hazard was tested for all variables. Logtransformed values of ADM and the APACHE score were evaluated in a multivariable Cox regression model to evaluate the contribution of ADM over and above that of APACHE alone based on nested models. The predictive value of each model was assessed by the model likelihood ratio chi-square statistic. The concordance index ( $\mathrm{C}$ index)

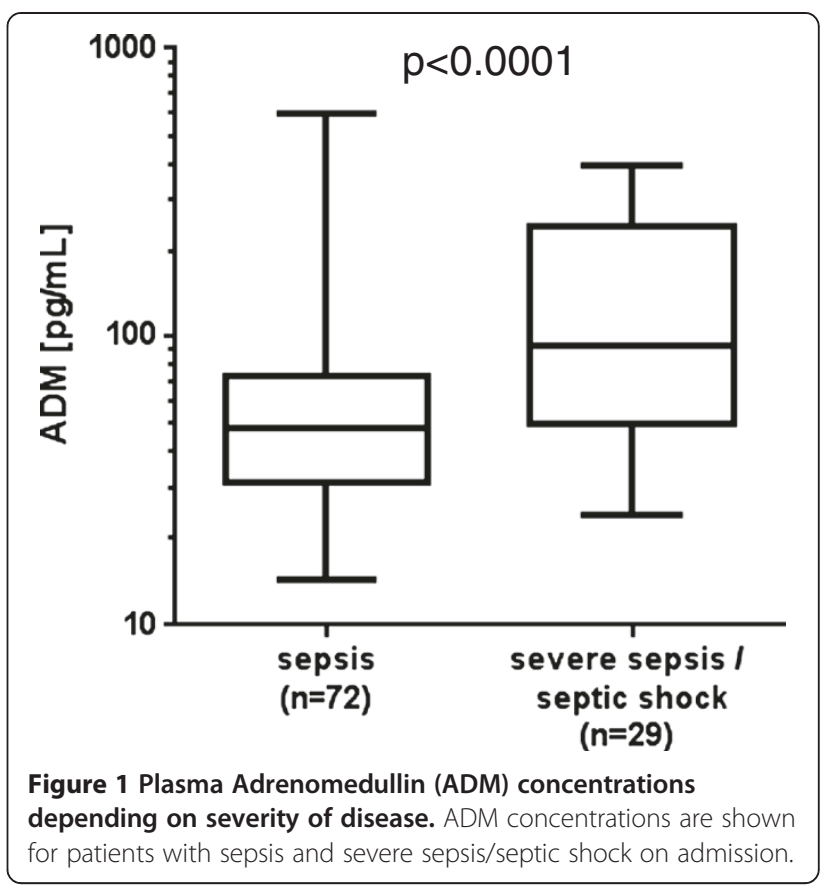

is given as an effect measure. Survival curves plotted by the Kaplan-Meier method were used for illustration. All statistical tests were two-tailed and a two-sided $P$-value of 0.05 was considered significant. The statistical analyses were performed using $\mathrm{R}$ version 2.5.1.

\section{Results}

At the time of admission, ADM concentrations were associated with the severity of disease: ADM was

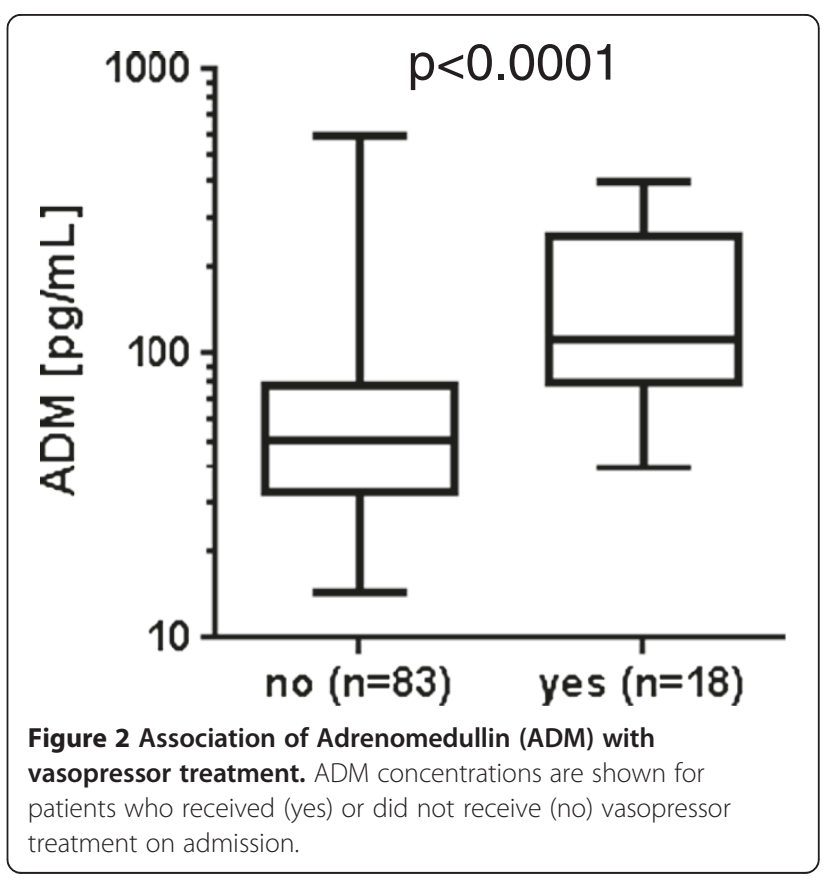


Table 2 Association of several variables obtained on admission with 28-day mortality

\begin{tabular}{|c|c|c|c|}
\hline Variable & Died within 28 days $(n=29)$ & Survived 28 days $(n=72)$ & $P$-value \\
\hline ADM, pg/mL, median (IQR) & 83.8 (48.3 to 232 ) & $50(31.2$ to 77$)$ & $<0.001$ \\
\hline $\mathrm{PCT}, \mathrm{ng} / \mathrm{mL}$, median (IQR) & $4.8(1.4$ to 13.9$)$ & $2.2(0.6$ to 8.9$)$ & 0.0523 \\
\hline Creatinine clearance, $\mathrm{mL} /$ minute, median (IQR) & 31.5 (16 to 68$)$ & 56 (28 to 81$)$ & 0.0539 \\
\hline Creatinine, mg/dL, median (IQR) & $1.8(1$ to 3.1$)$ & $1.25(0.9$ to 2.1$)$ & 0.0922 \\
\hline CRP, mg/dL, median (IQR) & 17.4 (6.8 to 26.9) & 14.5 (6.4 to 23.5$)$ & 0.7114 \\
\hline White cells, $10^{9}$ cells/L, median (IQR) & $11.0(26.5$ to 17.2$)$ & $13.3(8.1$ to 17.7$)$ & 0.2416 \\
\hline Platelets, $10^{9}$ cells $/ \mathrm{L}$, median (IQR) & 185 (127 to 237$)$ & 217 (162 to 299$)$ & 0.0979 \\
\hline APACHE II score, points, median (IQR) & $22(18$ to 27$)$ & $14(12$ to 18$)$ & $<0.001$ \\
\hline
\end{tabular}

ADM, Adrenomedullin; PCT, Procalcitonin; CRP, C-reactive protein; APACHE II, acute physiology and chronic health evaluation II.

correlated with the APACHE II score $(r=0.46 ; P<0.0001)$, and were significantly $(P<0.001)$ higher in patients presenting with severe sepsis or septic shock (93 (50 to 232) $\mathrm{pg} / \mathrm{mL}$ ) compared to those with sepsis only (48 (32 to 72) $\mathrm{pg} / \mathrm{mL}, P<0.0001$ ) (Figure 1 ).

Admission ADM levels were negatively correlated with mean arterial pressure (MAP) $(r=-0.39 ; P<0.0001)$. Patients who required vasopressors on admission had significantly $(P<0.0001)$ higher ADM concentrations (129 (83 to 264) pg/mL) than those who did not require vasopressors infusion (48 (32 to 75$) \mathrm{pg} / \mathrm{mL}$ ) (Figure 2). There was a non-statistical trend toward higher ADM levels on admission (87 (44 to 133 ) $\mathrm{pg} / \mathrm{mL}$ ) in the four patients who later required vasopressor (87 (44 to 133) $\mathrm{pg} / \mathrm{mL}$ ) compared with those patients who did not receive vasopressor therapy during hospital stay (48 (32 to 72$) \mathrm{pg} / \mathrm{mL})(P=0.448)$.

Over the observation period of 28 days following admission, 29 of the 101 patients died (28\%). These patients had significantly higher admission ADM concentrations (84 (48 to 232) pg/mL) than the survivors (50 (31 to 77$) \mathrm{pg} / \mathrm{mL})(P<0.001)$ (Table 2$)$. Median (IQR) of the APACHE II score was 22 (18 to 27) in non-survivors and $14(12$ to 18$)$ in survivors $(P<0.001)$. For the discrimination of survivors from non-survivors PCT and creatinine clearance were borderline significant $(P=0.0523$ and $P=0.0539)$. Admission ADM levels were higher in patients who died in the hospital due to septic shock (177 (77 to 289$) \mathrm{pg} / \mathrm{mL}$ ) than in patients who died in the hospital due to other causes (54 (45 to 96$) \mathrm{pg} / \mathrm{mL}$ ) $(P=0.04)$ (Figure 3).

The standardized hazard ratio (HR) from the Cox regression model of continuous ADM levels at admission for predicting 28-day mortality was 2.6; ( $\mathrm{C}$ index) area under the curve $(\mathrm{AUC})=0.69 ; \chi^{2}=18.2 ; P<0.0001$. For the APACHE II score, the results from Cox regression analysis were ( $\mathrm{C}$ index) $\mathrm{AUC}=0.75 ; \mathrm{X}^{2}=22.2 ; P<0.0001$ ). ADM was independent from APACHE II and provided additional prognostic information (added $X^{2}=5.2 ; P=0.02$ ). From a subset of 65 patients admission levels of MRproADM were available. In the Cox regression model for predicting 28-day mortality MR-proADM performed worse $\left((C\right.$ index $)$ AUC $\left.\left.=0.60 ; \chi^{2}=1.46 ; P<0.22\right)\right)$ than $\operatorname{ADM}\left((C\right.$ index $\left.\left.) \mathrm{AUC}=0.74 ; \chi^{2}=13.9 ; P<0.00019\right)\right)$.

We further assessed whether additional serial measurements of ADM in patients during their hospital stay would improve the prognostic value of ADM measurement on admission. The $\mathrm{C}$ index for predicting mortality continuously increased, the later ADM was measured (Table 3, $P<0.01$ for added value of ADM on days 3 and 4 on top of ADM on admission). The potential value of serial ADM measurement is illustrated in Figure 4: patients with an ADM admission concentration of above $70 \mathrm{pg} / \mathrm{mL}$ had a 28 -day survival rate of $55 \%$. For those patients from this group whose ADM concentration had remained above

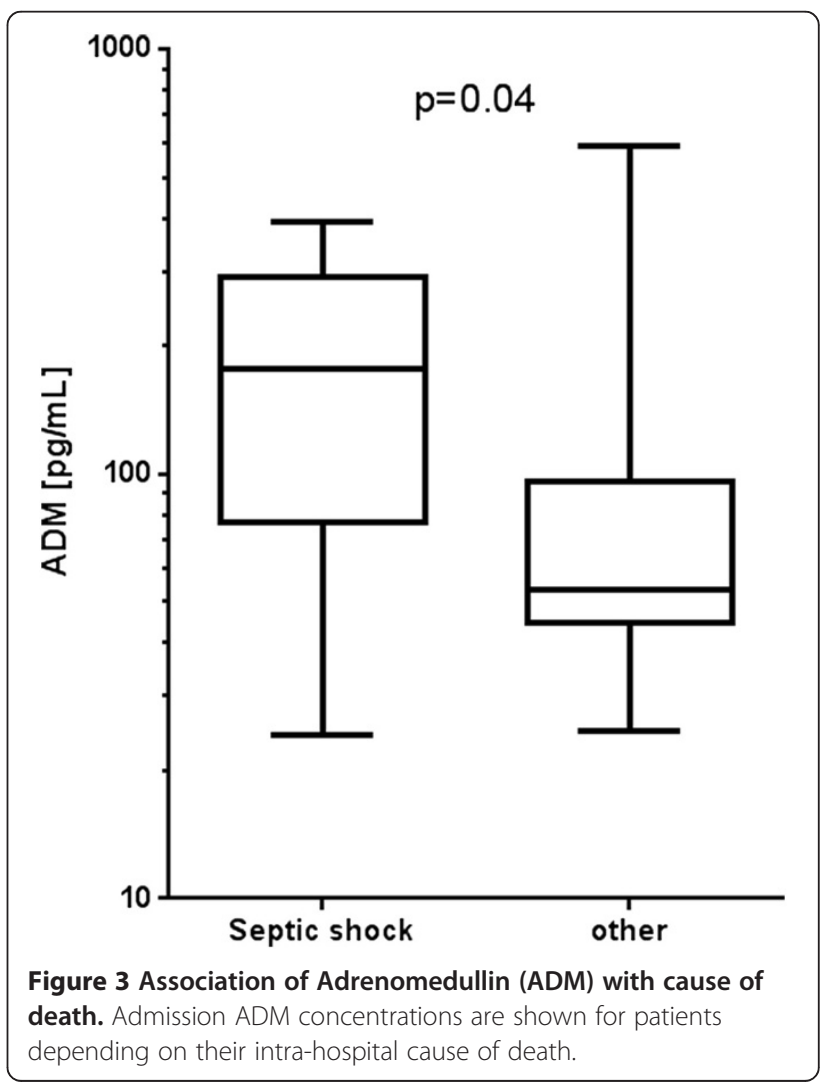


Table 3 Cox regression analysis for prediction of 28-day mortality

\begin{tabular}{lllll}
\hline Variable & $\mathbf{X}^{\mathbf{2}}$ & $\boldsymbol{P}$-value & $\mathbf{C}$ index (AUC) & $\boldsymbol{P}$-value of added value on top of ADM on admission \\
\hline ADM, admission & 18.2 & $<0.0001$ & 0.69 & - \\
ADM, day 1 & 21.2 & $<0.0001$ & 0.70 & 0.079 \\
ADM, day 2 & 20.5 & $<0.0001$ & 0.72 & 0.113 \\
ADM, day 3 & 26.4 & $<0.0001$ & 0.74 & 0.004 \\
ADM, day 4 & 29.9 & $<0.0001$ & 0.75 & $<0.001$ \\
\hline
\end{tabular}

If follow up data were missing, the last observation was carried forward. ADM, Adrenomedullin; AUC, area under the curve.

$70 \mathrm{pg} / \mathrm{mL}$ every day until 4 days after admission, the survival rate was $36 \%$. In contrast, when ADM levels had decreased to concentrations below $70 \mathrm{pg} / \mathrm{mL}$ the survival rate was $100 \%$.

\section{Discussion}

Using a novel ADM sandwich immunoassay, which selectively detects the bioactive C-terminally amidated ADM variant, this study demonstrates that plasma ADM levels in septic patients admitted to the ED increase with the severity of disease, correlate with the requirement for vasopressor therapy, and are associated with the 28-day mortality rate similar to APACHE II.

Although plasma ADM levels have been previously assessed in several small studies of septic patients [9,15-17], the assays used required large sample volumes, sample extraction, and long incubation times. Moreover, the technical validity of these competitive radioimmunoassays has been questioned [21]. Thus, there are restrictions with interpreting the ADM data of these studies due to the limited number of patients investigated and the type of
ADM assays used, and consequently, the true potential clinical value of ADM measurement in septic patients has been difficult to judge. Measurement of a stable fragment of the ADM precursor peptide, namely MRproADM, has been introduced to circumvent some of these existing problems [22-24]. However, conceptually, using MR-proADM as a surrogate for ADM has limitations: It does not reflect potential imbalances between the non-functional glycine-extended and the bioactive amidated ADM, and it must be assumed to have different clearing kinetics to ADM.

In the present study we demonstrated a strong association of admission ADM levels with the severity of the disease, supporting an earlier report describing elevated ADM levels in those with severe sepsis and those with septic shock [15]. It also supports several studies where MRproADM was used as surrogate marker for ADM $[7,23]$.

It is interesting that although ADM is known to be a potent vasodilator, in the present study it was negatively correlated to MAP, with a strong association to the need for vasopressor therapy. A correlation of plasma ADM

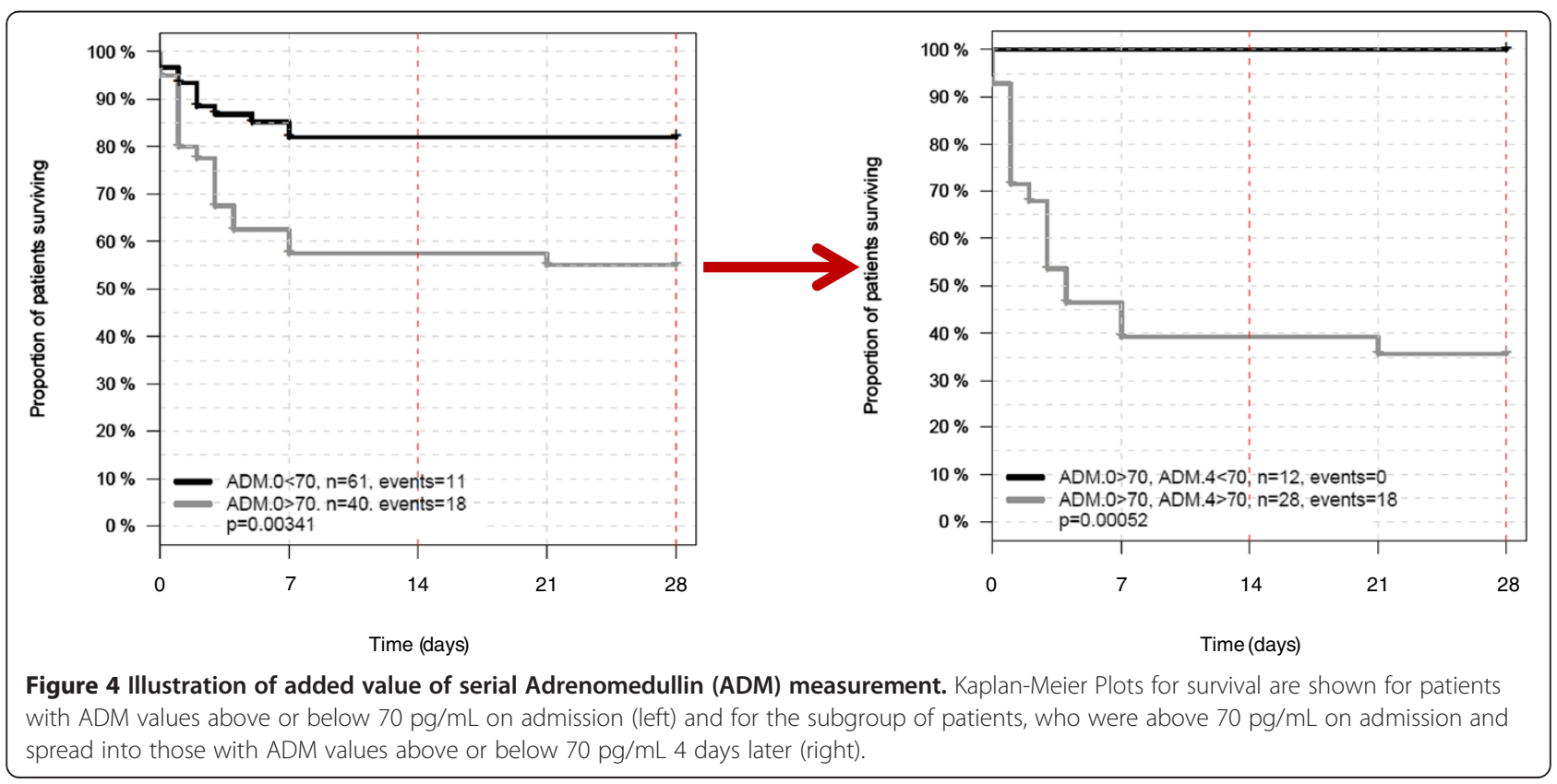


in septic shock patients with the relaxation of vascular tone has been previously observed [17]. In our study, the patients who only later developed the need for vasopressor therapy actually had elevated ADM levels at admission. Clearly, a larger study is needed to confirm that elevation of $\mathrm{ADM}$ precedes the requirement for vasopressor therapy. If confirmed, measurement of ADM could become a helpful additional tool to guide vasopressor therapy.

In one study investigating only 12 septic patients, admission ADM did not distinguish survivors from non-survivors and did not correlate with mean arterial pressure [9]. Our much larger study with a more robust assay demonstrates that ADM levels on admission were strongly associated with the 28-day mortality rate. In fact, ADM was superior over PCT, creatinine clearance and, albeit tested only in a subset of patients, MR-proADM. Admission ADM levels were higher in those who died from septic shock in the hospital compared to other causes of death.

Using Cox regression analysis we could demonstrate that the accuracy for predicting mortality with plasma ADM levels increases, the later the ADM measured is made during the hospital stay. This indicates that serial measurement of ADM may add important information to admission levels and ADM might be suitable for therapy monitoring of sepsis patients. We illustrated the potential of monitoring using ADM by applying a cut off value of $70 \mathrm{pg} / \mathrm{mL}$, which is close to the 99th percentile of the normal range $(43 \mathrm{pg} / \mathrm{mL})$ : patients who were admitted with ADM levels above $70 \mathrm{pg} / \mathrm{mL}$ had a 28-day survival rate of $55 \%$. For those patients from this group, whose ADM levels dropped to levels below $70 \mathrm{pg} / \mathrm{mL} 4$ days later, the survival rate was $100 \%$. The cut off was selected retrospectively as an example for how to distinguish groups with different risks to experience an adverse outcome depending on serial development of a biomarker concentration. The optimal cut off needs to be validated in future studies.

\section{Conclusions}

In patients admitted to the ED with sepsis, severe sepsis, or septic shock, plasma ADM assessment is strongly associated with severity of disease, vasopressor requirement and 28-day mortality. Further research is warranted to assess in more depth the possible clinical utility of ADM measurement in patients hospitalized with sepsis.

\section{Key messages}

- In sepsis patients admitted to the ED, mature plasma (ADM) measured by a novel sandwich immunoassay, is associated with severity of disease, 28-day mortality rate (independent from and additive to APACHE II), and requirement for vasopressor therapy.

- Serial measurement of ADM improves mortality risk prediction.

\section{Abbreviations}

ADM: Adrenomedullin; APACHE: II acute physiology and chronic health evaluation II; BSA: bovine serum albumin; CRP: C-reactive protein; ED: Emergency Department; EDTA: ethylenediaminetetraacetic acid; HPLC: high-performance

liquid chromatography; MAP: mean arterial pressure; PCT: Procalcitonin; SIRS: systemic inflammatory response syndrome.

\section{Competing interests}

University La Sapienza Rome, Sant'Andrea Hospital, received a research grant from Sphingotec GmbH for this study. Andreas Bergmann is General Manager of Sphingotec GmbH and owns shares of Sphingotec $\mathrm{GmbH}$. Sphingotec $\mathrm{GmbH}$ holds patent rights on the Adrenomedullin assay. Joachim Struck is employed by Sphingotec GmbH.

\section{Authors' contributions}

RM and LM recruited the patients, and obtained samples, clinical and laboratory variables. JS, RM, ASM and AB evaluated the data and drafted the manuscript. $A B$ and SD conceived of the study, and participated in its design and coordination. All authors revised, read and approved the final manuscript.

\section{Acknowledgements}

We like to thank Janine Sachse for excellent technical assistance. This study was supported by Project Grants of the Federal State of Brandenburg and European Regional Development Funds (EFRE).

\section{Author details}

${ }^{1}$ University La Sapienza Rome, Sant'Andrea Hospital, Rome, Italy. ${ }^{2}$ Adrenomed AG, Hennigsdorf, Germany. ${ }^{3}$ Sphingotec GmbH, Hennigsdorf, Germany.

${ }^{4}$ Veterans Affairs San Diego Healthcare System, San Diego, CA, USA.

Received: 30 September 2013 Accepted: 11 February 2014 Published: 17 February 2014

\section{References}

1. Angus DC, Linde-Zwirble WT, Lidicker J, Clermont G, Carcillo J, Pinsky MR: Epidemiology of severe sepsis in the United States: analysis of incidence, outcome, and associated costs of care. Crit Care Med 2001, 29:1303-1310.

2. Martin GS, Mannino DM, Eaton S, Moss M: The epidemiology of sepsis in the United States from 1979 through 2000. N Engl J Med 2003, 348:1546-1554.

3. Vincent JL, Sakr Y, Sprung CL, Ranieri VM, Reinhart K, Gerlach H, Moreno R, Carlet J, Le Gall JR, Payen D, Sepsis Occurrence in Acutely III Patients Investigators: Sepsis in European intensive care units: results of the SOAP study. Crit Care Med 2006, 34:344-353.

4. Vincent JL: Sepsis definitions. Lancet Infect Dis 2002, 2:135.

5. Dellinger RP, Levy MM, Rhodes A, Annane D, Gerlach H, Opal SM, Sevransky JE, Sprung CL, Douglas IS, Jaeschke R, Osborn TM, Nunnally ME, Townsend SR, Reinhart K, Kleinpell RM, Angus DC, Surviving Sepsis Campaign Guidelines Committee including the Pediatric Subgroup: Surviving sepsis campaign: international guidelines for management of severe sepsis and septic shock: 2012. Crit Care Med 2013, 41(2):580-637.

6. Magrini L, Travaglino F, Marino R, Ferri E, De Berardinis B, Cardelli P, Salerno G, Di Somma S: Procalcitonin variations after Emergency Department admission are highly predictive of hospital mortality in patients with acute infectious diseases. Eur Rev Med Pharmacol Sci 2013, 17:133-142.

7. Travaglino F, De Berardinis B, Magrini L, Bongiovanni C, Candelli M, Silveri NG, Legramante J, Galante A, Salerno G, Cardelli P, Di Somma S: Utility of Procalcitonin (PCT) and Mid regional pro-Adrenomedullin (MR-proADM) in risk stratification of critically ill febrile patients in Emergency Department (ED). A comparison with APACHE II score. BMC Infect Dis 2012, 12:184.

8. Kitamura K, Kangawa K, Kawamoto M, Ichiki Y, Nakamura S, Matsuo H, Eto T: Adrenomedullin: a novel hypotensive peptide isolated from human pheochromocytoma. Biochem Biophys Res Commun 1993, 192:553-560.

9. Hirata Y, Mitaka C, Sato K, Nagura T, Tsunoda Y, Amaha K, Marumo F: Increased circulating adrenomedullin, a novel vasodilatory peptide, in sepsis. J Clin Endocrinol Metab 1996, 81:1449-1453.

10. Beltowski J, Jamroz A: Adrenomedullin-what do we know 10 years since its discovery? Pol J Pharmacol 2004, 56:5-27.

11. Hinson JP, Kapas S, Smith DM: Adrenomedullin, a multifunctional regulatory peptide. Endocr Rev 2000, 21:138-167.

12. Wong LY, Cheung BM, Li YY, Tang F: Adrenomedullin is both proinflammatory and antiinflammatory: its effects on gene expression 
and secretion of cytokines and macrophage migration inhibitory factor in NR8383 macrophage cell line. Endocrinology 2005, 146:1321-1327.

13. Koo DJ, Zhou M, Chaudry IH, Wang P: The role of adrenomedullin in producing differential hemodynamic responses during sepsis. J Surg Res 2001, 95:207-218.

14. Wang P, Ba ZF, Cioffi WG, Bland Kl, Chaudry IH: The pivotal role of adrenomedullin in producing hyperdynamic circulation during the early stage of sepsis. Arch Surg 1998, 133:1298-1304.

15. Ueda S, Nishio K, Minamino N, Kubo A, Akai Y, Kangawa K, Matsuo H, Fujimura Y, Yoshioka A, Masui K, Doi N, Murao Y, Miyamoto S: Increased plasma levels of adrenomedullin in patients with systemic inflammatory response syndrome. Am J Respir Crit Care Med 1999, 160(1):132-136.

16. Ehlenz K, Koch B, Preuss P, Simon B, Koop I, Lang RE: High levels of circulating adrenomedullin in severe illness: correlation with C-reactive protein and evidence against the adrenal medulla as site of origin. Exp Clin Endocrinol Diabetes 1997, 105:156-162.

17. Nishio K, Akai Y, Murao Y, Doi N, Ueda S, Tabuse H, Miyamoto S, Dohi K, Minamino N, Shoji H, Kitamura K, Kangawa K, Matsuo H: Increased plasma concentrations of adrenomedullin correlate with relaxation of vascular tone in patients with septic shock. Crit Care Med 1997, 25(6):953-957.

18. Di Somma S, Magrini L, Travaglino F, Lalle I, Fiotti N, Cervellin G, Avanzi GC, Lupia E, Maisel A, Hein F, Wagner F, Lippi G: Opinion paper on innovative approach of biomarkers for infectious diseases and sepsis management in the emergency department. Clin Chem Lab Med 2013, 51(6):1167-1175.

19. Dellinger RP, Levy MM, Carlet JM, Bion J, Parker MM, Jaeschke R, Reinhart K, Angus DC, Brun-Buisson C, Beale R, Calandra T, Dhainaut JF, Gerlach H, Harvey M, Marini JJ, Marshall J, Ranieri M, Ramsay G, Sevransky J, Thompson BT, Townsend S, Vender JS, Zimmerman JL, Vincent JL, International Surviving Sepsis Campaign Guidelines Committee, American Association of CriticalCare Nurses, American College of Chest Physicians, American College of Emergency Physicians, Canadian Critical Care Society, European Society Clinical Microbiology and Infectious Diseases, European Society of Intensive Care Medicine, European Respiratory Society, International Sepsis Forum, Japanese Association for Acute Medicine, Japanese Society of Intensive Care Medicine, Society of Critical Care Medicine, Society of Hospital Medicine, Surgical Infection Society, World Federation of Societies of Intensive and Critical Care Medicine: Surviving Sepsis Campaign: international guidelines for management of severe sepsis and septic shock: 2008. Crit Care Med 2008, 36(1):296-327.

20. Knaus WA, Draper EA, Wagner DP, Zimmerman JE: APACHE II: a severity of disease classification system. Crit Care Med 1985, 13:818-829.

21. Lewis LK, Smith MW, Yandle TG, Richards AM, Nicholls MG: Adrenomedullin (1-52) measured in human plasma by radioimmunoassay: plasma concentration, adsorption, and storage. Clin Chem 1998, 44:571-577.

22. Morgenthaler NG, Struck J, Alonso C, Bergmann A: Measurement of midregional proadrenomedullin in plasma with an immunoluminometric assay. Clin Chem 1823-1829, 2005:51.

23. Christ-Crain M, Morgenthaler NG, Struck J, Harbarth S, Bergmann A, Muller B: Mid-regional pro-adrenomedullin as a prognostic marker in sepsis: an observational study. Crit Care 2005, 9:R816-R824.

24. Struck J, Tao C, Morgenthaler NG, Bergmann A: Identification of an Adrenomedullin precursor fragment in plasma of sepsis patients. Peptides 2004, 25:1369-1372.

\section{doi:10.1186/cc1373}

Cite this article as: Marino et al:: Plasma adrenomedullin is associated with short-term mortality and vasopressor requirement in patients admitted with sepsis. Critical Care 2014 18:R34.

\section{Submit your next manuscript to BioMed Central and take full advantage of:}

- Convenient online submission

- Thorough peer review

- No space constraints or color figure charges

- Immediate publication on acceptance

- Inclusion in PubMed, CAS, Scopus and Google Scholar

- Research which is freely available for redistribution

Submit your manuscript at www.biomedcentral.com/submit
C Biomed Central 